\title{
New infant cranium from the African Miocene sheds light on ape evolution
}

Isaiah Nengo $^{1,2}$, Paul Tafforeau ${ }^{3}$, Christopher C. Gilbert ${ }^{4,5,6}$, John G. Fleagle ${ }^{7}$, Ellen R. Miller ${ }^{8}$, Craig Feibel ${ }^{9,10}$, David Fox ${ }^{11}$, Josh Feinberg ${ }^{11}$, Kelsey D. Pugh ${ }^{5,6}$, Camille Berruyer $^{3}$, Sara Mana ${ }^{12}$, Zachary Engle ${ }^{10} \&$ Fred Spoor $^{13,14}$

${ }^{1}$ Department of Anthropology, De Anza College, Cupertino, California 95104, USA.

${ }^{2}$ Turkana Basin Institute, Social and Behavioral Sciences Building N-507, Stony Brook University, New York, New York 11794-4364, USA.

${ }^{3}$ European Synchrotron Radiation Facility, CS-40220, F-38043 Grenoble Cedex 09, France.

${ }^{4}$ Department of Anthropology, Hunter College of the City University of New York, 695 Park Avenue, New York, New York 10065, USA.

${ }^{5}$ The Graduate Center of the City University of New York, 3655 th Avenue, New York, New York 10016, USA.

${ }^{6}$ New York Consortium in Evolutionary Primatology, New York, New York, USA.

${ }^{7}$ Department of Anatomical Sciences, Health Sciences Center, Stony Brook University, Stony Brook, New York 11794-8081, USA.

${ }^{8}$ Department of Anthropology, Wake Forest University, Winston Salem, North Carolina 27109-7807, USA.

${ }^{9}$ Departments of Anthropology, Rutgers University, New Brunswick, New Jersey 08901-1414, USA.

${ }^{10}$ Department of Earth and Planetary Sciences, Rutgers University, Piscataway, New Jersey 08854-8066, USA.

${ }^{11}$ Department of Earth Sciences, University of Minnesota, Minneapolis, Minnesota 55455, USA.

${ }^{12}$ Department of Geological Sciences, Salem State University, Salem, Massachusetts 01970, USA.

${ }^{13}$ Department of Cell and Developmental Biology, University College London, London WC1E 6BT, UK.

${ }^{14}$ Department of Human Evolution, Max Planck Institute for Evolutionary Anthropology, Leipzig 04103, Germany.

The evolutionary history of extant hominoids (humans and apes) remains poorly understood. The African fossil record during the crucial time period, the Miocene epoch, largely comprises isolated jaws and teeth, and little is known about ape cranial evolution. Here we report on the most complete fossil ape cranium yet known, recovered from the 13 million-year-old Middle Miocene site of Napudet, Kenya. The infant specimen, KNM-NP 59050, is assigned to a new species of Nyanzapithecus on the basis of its unerupted permanent teeth, visualized by synchrotron imaging. Its ear canal has a fully ossified tubular ectotympanic, a derived feature linking the species with crown catarrhines. Although it resembles some hylobatids in aspects of its morphology 
and dental development, it possesses no definitive hylobatid synapomorphies. The combined evidence suggests that nyanzapithecines were stem hominoids close to the origin of extant apes, and that hylobatid-like facial features evolved multiple times during catarrhine evolution.

Hominoids underwent a major evolutionary radiation during the Miocene epoch, with over 40 widely recognized species in at least 30 genera $^{1}$. Despite this multitude of taxa, only about one-third are known from any cranial remains, and no more than half a dozen preserve any significant portion beyond the face and palate ${ }^{2}$. Thus, much about hominoid cranial evolution remains poorly understood, especially with respect to the ancestral morphology that gave rise to the clade containing extant apes and humans. Importantly, the African fossil record lacks any reasonably complete hominoid crania between 17 and 7 million years (Myr) ago, and no cranial specimens are known at all from between 14 and 10 Myr (refs 3-6), greatly hampering the analysis of hominoid evolution. The KNM-NP 59050 cranium reported here was recovered from Napudet (South Turkana, Kenya) and dated to $13 \mathrm{Myr}$; it thus falls within this critical yet poorly represented period. The infant specimen is nearly complete, but is missing the deciduous dental crowns (Fig. 1a-d and Extended Data Fig. 1a-f). The unerupted adult dentition, brain endocast, and bony labyrinths were visualized using propagation phase-contrast X-ray synchrotron microtomography (PPC-SR- $\mu C T$; Fig. 1e-h) ${ }^{7}$. The crown morphology of the fully formed $\mathrm{I}^{1} \mathrm{~s}$ and $\mathrm{M}^{1} \mathrm{~s}$, as well as the partly formed $\mathrm{M}^{2} \mathrm{~s}$ (Fig. 2 and Supplementary Data 1), indicate that the specimen warrants attribution to a new species in the genus Nyanzapithecus.

\section{Systematic palaeontology}

Order Primates Linneaus, 1758

Suborder Anthropoidea Mivart, 1864

Infraorder Catarrhini Geoffroy, 1812

Superfamily Hominoidea Gray, 1825

Subfamily Nyanzapithecinae Harrison, 2002

Genus Nyanzapithecus Harrison, 1986

Nyanzapithecus alesi sp. nov.

Etymology. Specific name taken from the Turkana word for ancestor, Ales. 
Holotype. KNM-NP 59050, an almost complete infant cranium preserving fully formed but unerupted $\mathrm{I}^{1}$ and $\mathrm{M}^{1}$ crowns, as well as partly formed crowns of all other permanent teeth, except the not yet initiated $\mathrm{M}^{3} \mathrm{~s}$.

Locality and horizon. Napudet $\left(2^{\circ} 57^{\prime} \mathrm{N}, 35^{\circ} 52^{\prime} \mathrm{E}\right)$, Turkana Basin, Kenya, Emunyan Beds, Brown Bedded Tuffs (Extended Data Fig. 2a).

Geological age. 13 Myr.

Diagnosis. A large species of Nyanzapithecus, with $\mathrm{M}^{1}$ significantly larger than in $N$. pickfordi $(P<0.05)$, N. harrisoni $(P<0.01)$, and probably $N$. vancouveringorum (Fig. 3a and Extended Data Table 1a; one-tailed $t$-test, Bonferroni corrected). The upper molars of $N$. alesi differ from those of $N$. vancouveringorum in being more waisted, and in having higher and more inflated molar cusps, a very restricted trigon, and a mesial shelf. $N$. alesi differs from $N$. vancouveringorum and $N$. harrisoni in having an $\mathrm{M}^{1}$ with a paracone approximately the same size as the metacone, and a protocone much larger than the hypocone. A reduced lingual cingulum also distinguishes $N$. alesi from $N$. harrisoni, but not from either $N$. vancoveringorum or $N$. pickfordi. N. alesi further differs from $N$. pickfordi in that the prehypocrista of the $\mathrm{M}^{1}$ meets the base of the protocone rather than the crista obliqua.

\section{Cranial morphology}

KNM-NP 59050 is a nearly complete but somewhat distorted cranium of an infant primate (Fig. 1). The cranium is slightly crushed bilaterally and the posterior portion of the basicranium is both broken and distorted. All the deciduous tooth crowns are broken off, but their roots are preserved. The permanent teeth are unerupted, with the right $\mathrm{I}^{1}$ being visible in its crypt.

The overall dimensions of KNM-NP 59050 are similar to those of Symphalangus crania of equivalent dental age, except for the maxillo-alveolar size, which is similar to Hoolock (Extended Data Table 1b). Relative to overall cranial size, the snout is small as in juvenile hylobatids, and smaller than in extant juvenile hominids (Extended Data Figs 3 and $4 \mathrm{a}-\mathrm{c}$ ). This difference between hylobatids and hominids persists into adulthood (Extended Data Fig. 4b, d), and assuming that $N$. alesi followed the same pattern, its snout would have been relatively small as an adult, unlike that of Afropithecus and Saadanius.

The orbits appear large, but are well within the expected range for an extant juvenile hominoid of its size (Extended Data Fig. 4e). The orbits are slightly taller than wide, which may reflect the bilateral distortion (Extended Data Fig. 3a, b). The supraorbital costae/ridges 
are poorly defined, similar to other infants, and in contrast to the condition observed in most adult extant hominoids. The lateral and inferior margins of the orbit are protruding and barlike, which is unlike the flat/continuous margin seen among infant and adult great apes but similar to the morphology observed in hylobatids (infants and adults), pliopithecoids, and, to a lesser extent, Micropithecus ${ }^{8}$. The consistency of this feature among extant adult and juvenile apes suggests that it is ontogenetically stable. The interorbital area is relatively wide compared with the condition in extant juvenile hominids, but near the mean width for juvenile hylobatids, again a pattern probably maintained into adulthood and seen in Afropithecus and Turkanapithecus (Extended Data Fig. 5a, b). The lacrimal fossa is in line with the medial orbital margin, as in extant hylobatids and Victoriapithecus, rather than being clearly within the orbit as in Pan and Gorilla, or clearly anterior to the orbital margin as commonly seen in Aegyptopithecus ${ }^{9}$. Nasion is located about a third of the way down between the levels of the inferior and superior orbital margins. Although the edge of the nasal aperture is broken, it is likely that the premaxillae ended at the lower edge of the nasals, as in other Miocene hominoids ${ }^{10}$, but unlike the condition seen in most cercopithecoids, juvenile or adult, or Aegyptopithecus, where the premaxillae extend superiorly between the nasals and the maxillae. The nasals are tall and rectangular; they do not appear to be hour-glass or diamond-shaped, as in chimpanzees of all ages, or to broaden inferiorly as in some cercopithecoids and gorillas (infants and adults). The nasal aperture is relatively narrow, as in Pongo (Extended Data Fig. 5c, d), and close to the width of the premaxillae.

The malar region is oriented posteroinferiorly, as in adult hylobatids and many extant juvenile catarrhines, contrasting with a more vertical or anteroinferior orientation in most adult Old World anthropoids, including pliopithecoids, Victoriapithecus, Ekembo, and Turkanapithecus. In extant catarrhine taxa, malar orientation changes during ontogeny, becoming more anteroinferior by adulthood. This makes it difficult to predict what the adult condition in KNM-NP 59050 would have looked like, but the preserved morphology is most similar to adult and juvenile hylobatids. The root of the zygomatic arch originates close to the alveolar margin, which is similar to the condition seen in Aegyptopithecus and Rangwapithecus, and probably reflects a primitive retention ${ }^{11}$. Other Miocene catarrhines, as well as hylobatids of all ages, vary in this feature. However, the inferior base of the zygomatic root is positioned relatively higher on the maxilla of juvenile and adult extant great apes, a notable distinction from many other catarrhines. 
The greatest cranial breadth is between the well-developed supramastoid crests, unlike in hylobatids of the same dental age, where the parietal bosses still project more laterally, and the crests are incipient (Extended Data Fig. 3b, c). The coronal suture appears to be oriented in a mediolateral direction, as in extant hominids, Ekembo, and Turkanapithecus. This contrasts with the anteriorly oriented, V-shape coronal suture seen in many cercopithecoids, platyrrhines, and hylobatids (Extended Data Fig. 3). Related to this configuration, the frontal is anteroposteriorly shorter than the parietal in the midsagittal plane (Extended Data Fig. 5e, f). The squamous portion of the left temporal is nearly a hemi-circle, with the highest point of the temporo-parietal suture near the anteroposterior middle of the bone, above the posterior root of the zygomatic arch, the glenoid fossa, and the external acoustic meatus. This condition is most similar to that seen in Symphalangus infants and adults, but it is different from the condition observed in other hylobatids and great apes, in which the suture is oriented horizontally or anteroinferiorly, respectively.

The external acoustic meatus is represented by a completely ossified tubular ectotympanic, unlike pliopithecoids and Pliobates, in which the inferior surface is not fully ossified $^{12}$. It is fused anteriorly to a prominent postglenoid process. The posterolateral orientation of the meatus is most similar to the condition seen in some great apes and cercopithecoids (infants and adults), but is different from that observed among hylobatids, where the ectotympanic is typically oriented more anterolaterally. The lateral pterygoid plates, well preserved on the right side, are large and extend from the maxillary tuberosities to the anteromedial edge of the glenoid fossa, as in Turkanapithecus. They are similar in size and shape to those observed in Symphalangus specimens at a similar stage of dental development, but are relatively larger than the lateral pterygoid plates of other extant hominoids, either immature or adult.

\section{Dental morphology and development}

The permanent dentition is unerupted and includes complete $\mathrm{I}^{1}$ and $\mathrm{M}^{1}$ crowns, along with partly formed crowns of $\mathrm{I}^{2}, \mathrm{C}-\mathrm{P}^{4}$, and nearly complete $\mathrm{M}^{2}$ crowns (Fig. 2 and Supplementary Data 1). The morphology of the $\mathrm{M}^{1}$ matches that described for the genus Nyanzapithecus ${ }^{13-15}$, but differs from previously described species of this genus as noted in the diagnosis. The molars are relatively high crowned, and both $\mathrm{M}^{1}$ and $\mathrm{M}^{2}$ display moderate crown waisting. The $\mathrm{M}^{2}$ is larger than $\mathrm{M}^{1}$, possesses a more prominent preprotocrista and prehypocrista compared with $\mathrm{M}^{1}$, and the $\mathrm{M}^{2}$ hypocone is positioned more distally relative to the other cusps than in $\mathrm{M}^{1}$. Both $\mathrm{M}^{1}$ and $\mathrm{M}^{2}$ have a crown diameter that is greater mesiodistally than 
buccolingually, and have the distinctive rhomboidal occlusal outline characteristic of other nyanzapithecines (Nyanzapithecus, Rangwapithecus, Turkanapithecus), Oreopithecus,

Samburupithecus, as well as some extant hominoid specimens (Fig. 3b). In fact, the $\mathrm{M}^{1}$ shape falls exclusively within the nyanzapithecine range among fossil taxa and the upper range of Symphalangus among extant taxa. The occlusal surfaces of the molars show conical, crowded, but well-defined cusps, combined with a relatively small, restricted trigon, and a distally offset hypocone. A prominent mesial cingulum is present, which continues around the protocone as a lingual cingulum, terminating at the hypocone. A short buccal cingulum is also present between the paracone and metacone. The occlusal surface enamel in KNM-NP 59050 is relatively smooth, with muted cuspal ridging and without the extensive wrinkling and cresting seen in Rangwapithecus.

The central incisor of KNM-NP 59050 is stout and the crown is spatulate, with the incisal-cervical long axis of the crown being canted mesially with respect to the long axis of the root. The lingual surface bears a strong cingulum that is angled incisally from distal to mesial, and prominent mesial and distal marginal ridges are present. The cingulum is continuous with the distal marginal ridge, but is separated from the mesial marginal ridge by a shallow cleft, creating a rectangular, arched fovea, with a distinct enamel bulb or tubercle at its superior-lingual edge. The mesiodistal length of the crown is short relative to the length of $\mathrm{M}^{1}$ (Fig. 3c), which is a distinctive feature found in Nyanzapithecus and hylobatids (Symphalangus, particularly). Overall, $\mathrm{I}^{1}$ is very similar in shape to the $\mathrm{I}^{1}$ of KNM-MB 11842, a fragmentary premaxilla/maxilla assigned to $N$. pickfordi ${ }^{13}$ (Extended Data Table 1), and Bar 217'02, an isolated upper left $\mathrm{I}^{1}$ assigned to $N$. cf. pickfordi ${ }^{16}$.

Dental development was analysed using synchrotron virtual histology ${ }^{17,18}$ (Extended Data Fig. 6). KNM-NP 59050 presents a long-period line periodicity of 5 days (Extended Data Fig. 6c), following expectations for a primate of this size ${ }^{19}$. The neonatal line was identified in the $\mathrm{M}^{1} \mathrm{~s}$ and the $\mathrm{I}^{1} \mathrm{~s}$, and a developmental sequence for the permanent teeth could be built using stress lines in dentine to match teeth (Fig. 4 and Extended Data Fig. 6). An age at death of $485 \pm 40$ days was established. The two-dimensional relative enamel thickness inde ${ }^{20}$ of the $\mathrm{M}^{1} \mathrm{~s}$, measured in the mesial developmental plane ${ }^{21}$, is 12.2 , which is intermediate between Symphalangus (10.8) and Hylobates (13.3) (ref. 22). KNM-NP 59050 shows an unusually advanced $\mathrm{I}^{1}$, developing at a similar speed to the $\mathrm{M}^{1}$. Among catarrhines, this pattern is found only in Hylobates ${ }^{23}$ and Hoolock but not in Symphalangus ${ }^{23}$ or Nomascus. 


\section{Endocranial volume, olfactory fossa, and inner ear}

A preliminary reconstruction of the cranium indicates an endocranial volume of $101 \mathrm{ml}$, which is projected to be close to the adult value if KNM-NP 59050 followed the correlation between brain growth and dental development seen in extant hylobatids (Extended Data Table 1b). Scaled against body mass (Supplementary Note 1), this endocranial volume is smaller than seen in hylobatids, and close to values obtained for Turkanapithecus and Oreopithecus (Extended Data Fig. 7a). The olfactory fossa is shallow and underneath the frontal lobes (Fig. 1h), as seen in extant catarrhines and unlike the larger and rostrally projecting fossae in Aegyptopithecus, Saadanius, Victoriapithecus ${ }^{24}$, and Afropithecus. The bony labyrinth of the inner ear is preserved on both sides. In primates, this structure fully matures before birth, and in KNM-NP 59050 the overall size is closer to that of hylobatids than to hominids (Extended Data Fig. 7c-n), reflecting similarities in cranial size. However, in shape the labyrinth of KNM-NP 59050 uniquely shares with extant great apes a distinctly low-arced anterior semicircular canal ${ }^{25}$ (Extended Data Fig. 7c-f and Supplementary Table 1). The lateral semicircular canal is low-arced as well, as seen in Pan and Pongo ${ }^{25}$ among extant hominoids, and in Oreopithecus and Aegyptopithecus among extinct catarrhines. The arc size of the lateral canal is small relative to those of the anterior and posterior ones, a feature observed in Aegyptopithecus, Saadanius, Oreopithecus, and Rudapithecus, but not in extant hominoids (Supplementary Table 1). Scaled against body mass, the semicircular canals are relatively small, as in extant great apes, Saadanius, Rudapithecus, and Hispanopithecus, and unlike the large canals of hylobatids ${ }^{26}$ (Extended Data Fig. 7b).

In summary, in addition to the dental features given in the species diagnosis, the cranium of $N$. alesi can be characterized by the following, ontogenetically stable morphology: spatulate incisors, enamel with a relative thickness index of 12.2, a relatively small snout, wide interorbital distance, protruding and bar-like inferior and lateral margins of the orbit, narrow nasal aperture, shallow maxillae, a zygomatic root that originates low on the maxilla, large pterygoid plates, external acoustic meatus represented by a fully ossified ectotympanic tube, shallow and non-projecting olfactory fossae, and semicircular canals that are smallarced relative to body mass. Several of these features are also shared among other related genera for which partial crania are known (for example, Oreopithecus and Turkanapithecus).

\section{Phylogenetic analysis}

The attribution of KNM-NP 59050 to Nyanzapithecus provides an opportunity to clarify the phylogenetic relationships of this relatively rare genus, on the basis of a much more 
comprehensive character evaluation than has been previously possible ${ }^{8,14,15,27}$. A cladistic analysis places $N$. alesi firmly within the nyanzapithecines, along with Rangwapithecus, Turkanapithecus, Oreopithecus, and Rukwapithecus; these genera, along with afropithecines, form part of a sister clade to the crown hominoids (Fig. 5 and Extended Data Fig. 8) rather than being stem catarrhines (contrary to ref. 15). A close relationship between Oreopithecus and Nyanzapithecus has been suggested previously on the basis of dental morphology ${ }^{13}$. Our analysis, which scores ontogenetically stable cranial characters for $N$. alesi, supports this hypothesis, in contrast to studies that place Oreopithecus among the crown hominoids ${ }^{28-31}$.

\section{Discussion}

KNM-NP 59050 is the first nearly complete African hominoid cranium recovered from between 17 and $7 \mathrm{Myr}$ ago, and the most complete Miocene ape cranium yet known. KNMNP 59050 provides critical evidence about the cranial anatomy of nyanzapithecines and, more broadly, of hominoids during an under-sampled time period in the African Miocene. Phylogenetic, cranial, and dental analyses of KNM-NP 50950 offer compelling insight into the ancestral morphology that gave rise to the clade containing extant apes and humans. $N$. alesi is similar to some hylobatids in aspects of overall cranial morphology and dental development, including enamel thickness, advanced $\mathrm{I}^{1}$ crown formation, and $\mathrm{M}^{1}$ crown formation time ${ }^{23}$. However, $N$. alesi is distinctly different from hylobatids in the relatively small size of its semicircular canals. This property is functionally relevant for the perception of motion, and suggests that $N$. alesi would have exhibited a slower, less agile mode of locomotion than the acrobatic brachiation of extant hylobatids ${ }^{26}$. This finding agrees with a previous study of a partial humerus provisionally attributed to Nyanzapithecus ${ }^{32}$. Some of the cranial similarities with extant hylobatids, including a relatively short face, a broad interorbital distance, and orbits with projecting inferior rims, are present not only in N. alesi, but also in other proposed nyanzapithecines, such as Turkanapithecus and Oreopithecus, as well as pliopithecoids, dendropithecoids, and colobines to varying degrees. This finding emphasizes the fact that multiple clades evolved hylobatid-like craniofacial morphology in parallel during catarrhine evolution. Hence, this general phenotype cannot be taken as evidence of shared ancestry with extant hylobatids in the absence of more convincing synapomorphies. As a case in point, our phylogenetic analysis suggests that the recently described Pliobates cataloniae, considered to be closely related to crown hominoids in part on the basis of hylobatid craniofacial similarities ${ }^{12}$, is more likely to be a member of the stem catarrhine group Pliopithecoidea (Fig. 5). 
Since its initial description over 30 years ago ${ }^{13}$, the catarrhine genus Nyanzapithecus has been known mostly from isolated dental specimens. KNM-NP 59050 represents the first substantial cranial material of Nyanzaptithecus, and it confirms that the genus, and nyanzapithecines more broadly, possess a fully ossified tubular ectotympanic, a derived feature linking the group with crown catarrhines relative to more primitive taxa such as pliopithecoids. KNM-NP 59050 is currently the only known specimen of the new species $N$. alesi. However, similarities in the size and shape of the $\mathrm{M}^{1}$ shared between N. alesi and isolated teeth previously referred to Nyanzapithecus $\mathrm{sp} .{ }^{33}$ or $N$. cf. pickfordi ${ }^{16}$ from Kipsaramon, Kenya (approximately 15.83-15.36 Myr (refs 33-35)) suggest that these specimens may also be part of the $N$. alesi hypodigm. Nyanzapithecines were a long-lived and diverse group of Miocene hominoids that are probably close to the origin of crown hominoids. They first appear in the fossil record during the latest Oligocene of Africa ${ }^{27}$, and persisted until perhaps the late Miocene, if the enigmatic Eurasian species Oreopithecus bamboli is indeed a late-surviving member of this clade ${ }^{13-15,28}$.

Received 19 March; accepted 4 July 2017.

Published online XX 2017.[Nature proofreader: please update when known.]

1. Fleagle, J. G. Primate Adaptation and Evolution, 3rd edn (Academic, 2013).

2. Begun, D. R. in Handbook of Paleoanthropology (eds Henke, W. \& Tattersall, I.) 1261-1332 (Springer, 2015).

3. Hill, A. \& Ward, S. C. Origin of the Hominidae: the record of African large hominoid evolution between 14 My and 4 My. Yearb. Phys. Anthropol. 31, 49-83 (1988).

4. Ward, S. C. \& Duren, D. in The Primate Fossil Record (ed. Hartwig, W. C.) 385-397 (Cambridge Univ. Press, 2002).

5. Bernor, R. L. New apes fill the gap. Proc. Natl Acad. Sci. USA 104, 19661-19662 (2007).

6. Lebatard, A. E. et al. Cosmogenic nuclide dating of Sahelanthropus tchadensis and Australopithecus bahrelghazali: Mio-Pliocene hominids from Chad. Proc. Natl Acad. Sci. USA 105, 3226-3231 (2008). 
7. Tafforeau, P. et al. Applications of X-ray synchrotron microtomography for nondestructive 3D studies of paleontological specimens. Appl. Phys. Adv. Mater. 83, 195-202 (2006).

8. Rossie, J. B. \& MacLatchy, L. A new pliopithecoid genus from the early Miocene of Uganda. J. Hum. Evol. 50, 568-586 (2006).

9. Benefit, B. R. \& McCrossin, M. L. The lacrimal fossa of cercopithecoidea, with special reference to cladistic analysis of Old World monkey relationships. Folia Primatol. 60, 133-145 (1993).

10. Rae, T. C. Mosaic evolution in the origin of the Hominoidea. Folia Primatol. 70, 125-135 (1999).

11. Benefit, B. R. \& McCrossin, M. L. Facial anatomy of Victoriapithecus and its relevance to the ancestral cranial morphology of Old World monkeys and apes. Am. J. Phys. Anthropol. 92, 329-370 (1993).

12. Alba, D. M. et al. Miocene small-bodied ape from Eurasia sheds light on hominoid evolution. Science 350, aab2625 (2015).

13. Harrison, T. New fossil anthropoids from the middle Miocene of East Africa and their bearing on the origin of the Oreopithecidae. Am. J. Phys. Anthropol. 71, 265284 (1986).

14. Harrison, T. in The Primate Fossil Record (ed. W. C. Hartwig) 311-338 (Cambridge Univ. Press, 2002).

15. Harrison, T. in Cenozoic Mammals of Africa (eds Werdelin, L. \& Sanders, W. J.) 429-469 (Univ. California Press, 2010).

16. Pickford, M. \& Kunimatsu, Y. Catarrhines from the Middle Miocene (ca. 14.5 Ma) of Kipsaraman, Tugen Hills, Kenya. Anthropol. Sci. 113, 189-224 (2005).

17. Tafforeau, P. \& Smith, T. M. Nondestructive imaging of hominoid dental microstructure using phase contrast X-ray synchrotron microtomography. J. Hum. Evol. 54, 272-278 (2008).

18. Smith, T. \& Tafforeau, P. New visions of dental tissue research: tooth development, chemistry, and structure. Evol. Anthropol. 17, 213-226 (2008). 
19. Bromage, T. G. et al. Lamellar bone is an incremental tissue reconciling enamel rhythms, body size, and organismal life history. Calcif. Tissue Int. 84, 388-404 (2009).

20. Martin, L. Significance of enamel thickness in hominoid evolution. Nature 314, 260 263 (1985).

21. Smith, T. M. et al. Dental evidence for ontogenetic differences between modern humans and Neanderthals. Proc. Natl Acad. Sci. USA 107, 20923-20928 (2010).

22. Olejniczak, A. J. Micro-Computed Tomography of Primate Molars. Ph.D. thesis, Stony Brook Univ. (2006).

23. Dirks, W. \& Bowman, J. E. Life history theory and dental development in four species of catarrhine primates. J. Hum. Evol. 53, 309-320 (2007).

24. Gonzales, L. A., Benefit, B. R., McCrossin, M. L. \& Spoor, F. Cerebral complexity preceded enlarged brain size and reduced olfactory bulbs in Old World monkeys. Nat. Commun. 6, 7580 (2015).

25. Spoor, F. \& Zonneveld, F. Comparative review of the human bony labyrinth. Am. J. Phys. Anthropol. 107 (Suppl. 27), 211-251 (1998).

26. Ryan, T. M. et al. Evolution of locomotion in Anthropoidea: the semicircular canal evidence. Proc. R. Soc. B 279, 3467-3475 (2012).

27. Stevens, N. J. et al. Palaeontological evidence for an Oligocene divergence between Old World monkeys and apes. Nature 497, 611-614 (2013).

28. Harrison, T. \& Rook, L. in Function, Phylogeny, and Fossils: Miocene Hominoid Evolution and Adaptations (eds Begun, D. R., Ward, C. V. \& Rose, M. D.) 327-362 (Plenum, 1997).

29. Begun, D. R., Ward, C. V. \& Rose, M. D. in Function, Phylogeny, and Fossils: Miocene Hominoid Evolution and Adaptations (eds Begun, D. R., Ward, C. V. \& Rose, M. D.) 389-415 (Plenum, 1997).

30. Begun, D. R. in Hominoid Evolution and Climate Change in Europe Vol. 2 (eds De Bonis, L., Koufos, G. \& Andrews, P.) 231-253 (Cambridge Univ. Press, 2001).

31. Begun, D. R., Nargolwalla, M. C. \& Kordos, L. European Miocene hominids and the origin of the African ape and human clade. Evol. Anthropol. 21, 10-23 (2012). 
32. McCrossin, M. L. An oreopithecid proximal humerus from the middle Miocene of Maboko Island, Kenya. Int. J. Primatol. 13, 659-677 (1992).

33. Kelley, J., Ward, S., Brown, B., Hill, A. \& Duren, D. L. Dental remains of Equatorius africanus from Kipsaramon, Tugen Hills, Baringo District, Kenya. $J$. Hum. Evol. 42, 39-62 (2002).

34. Behrensmeyer, A. K., Deino, A. L., Hill, A., Kingston, J. D. \& Saunders, J. J. Geology and geochronology of the middle Miocene Kipsaramon site complex, Muruyur Beds, Tugen Hills, Kenya. J. Hum. Evol. 42, 11-38 (2002).

35. Gilbert, C. C., Goble, E. D. \& Hill, A. Miocene Cercopithecoidea from the Tugen Hills, Kenya. J. Hum. Evol. 59, 465-483 (2010).

Supplementary Information is available in the online version of the paper.

Acknowledgements We thank the Government of Kenya for permission to do this research, the National Museums of Kenya, the American Museum of Natural History, Harvard Museum of Comparative Zoology, and the Digital Morphology Museum (KUPRI) for access to specimens in their care, and the Turkana Basin Institute for field support. The Leakey Foundation and trustee G. Getty, the Foothill-De Anza Foundation, De Anza College Design and Manufacturing Technologies Department, the National Geographic, the European Synchrotron Radiation Facility (beamline ID 19), and the Max Planck Society funded fieldwork or laboratory studies. We are grateful to M. Kibunjia and F. Manthi for facilitating permission to transport the specimen to Grenoble for scanning, and to E. Delson, M. Hill, J.-J. Hublin, D. Plotzki, and H. Temming for facilitating computed tomography scans of comparative specimens. We are grateful to R. David, M. Gilleland, L. Gonzales, T. Harrison, J. Kelley, Y. Kunimatsu, L. Martin, M. Leakey, K. O’Maley, M. Pickford, C. Rendiger, B. Sokhi, and A. Stoessel for help with this research. We thank the field crew, A. Ekes, B. Ewoi, J. Ekusi, A. Ekuon, C. Nyete, and T. Ngundo, for their tireless efforts in the field that led to the discovery of the specimen, C. Kiarie for preparing the fossil, and B. Monroy for preparing some of the graphics. We particularly thank J. Ekusi for discovering KNM-NP 59050.

Author Contributions I.N. and F.S. designed the study. I.N., C.F., E.R.M., and D.F. did field research. J.G.F., C.C.G., F.S., and K.D.P. collected and analysed the comparative data on gross dental and cranial morphology, and J.G.F. and C.C.G. prepared the diagnosis. P.T., C.B., and F.S. did the image analyses and made virtual reconstructions, P.T. and C.B. performed the dental development study, C.F., S.M., D.F., J.F., and Z.E. studied the geological context, and C.C.G. and K.D.P. did the phylogenetic analyses. F.S., I.N., and E.R.M. wrote the paper with contributions from C.C.G., P.T., and J.G.F.

Author Information Reprints and permissions information is available at www.nature.com/reprints. The authors declare no competing financial interests. Readers are welcome to comment on the online version of the paper. Publisher's note: Springer Nature remains neutral with regard to jurisdictional claims in published maps and institutional affiliations. Correspondence and requests for materials should be addressed to I.N. (Isaiah.Nengo@stonybrook.edu). 
Reviewer Information Nature thanks B. Benefit and the other anonymous reviewer(s) for their contribution to the peer review of this work.

Figure 1 KNM-NP 59050. a-d, Specimen as preserved in anterior view (a), superior view (b), inferior view (c), and left lateral view (d). e-h, Three-dimensional visualizations based on X-ray microtomography, in views matching $\mathbf{a}-\mathbf{d}$, and with the bone rendered transparent to show the deciduous dental roots (beige), the unerupted permanent tooth crowns (grey), the bony labyrinths (green), and the endocast (blue transparent in $\mathbf{e}-\mathbf{g}$ and beige in $\mathbf{h}$; the olfactory fossa marked by the blue line placed directly underneath). Scale bar, $5 \mathrm{~cm}$.

Figure 2 Unerupted permanent dentition. a-g, Three-dimensional X-ray microtomography-based visualization of the left $\mathrm{I}^{1}$ to $\mathrm{M}^{2}$, respectively, shown from left to right in occlusal, mesial, lingual, distal, buccal/labial views. $\mathbf{h}-\mathbf{n}$, The right $\mathrm{I}^{1}$ to $\mathrm{M}^{2}$ as shown for the left side. In occlusal view, the lingual side of the crown is down. Scale bar, $5 \mathrm{~mm}$.

Figure 3 Dental metric comparisons of KNM-NP 59050. a, $\mathrm{M}^{1}$ area (maximum mesiodistal $\times$ maximum buccolingual) compared with that of published Nyanzapithecus species. $\mathbf{b}, \mathrm{M}^{1}$ shape (maximum mesiodistal/maximum buccolingual, MD/BL) compared with extant and fossil hominoids. KNM-NP 59050 (dashed line) falls exclusively within the nyanzapithecine range among fossils. $\mathbf{c}$, Relative $\mathrm{I}^{1}$ size ( $\mathrm{I}^{1}$ maximum mesiodistal $/ \mathrm{M}^{1}$ maximum mesiodistal $)$ compared with extant and fossil hominoids. Nyanzapithecus, including KNM-NP 59050, falls closest to Symphalangus. Samples are given in Supplementary Data 2. For each sample the mean, the range between the first and third quartiles (box), and the highest and lowest values (whiskers) are indicated, with small ticks marking measured values in the sample.

Figure 4 Dental development of KNM-NP 59050. On the basis of virtual histological slices (Extended Data Fig. 6), the crown (green) and root (purple) development of the upper right dentition is plotted from prenatal initiation of the $\mathrm{M}^{1}$ and $\mathrm{I}^{1}$ to death at 485 days after birth. In addition to birth (magenta) and death (black), the coloured lines represent reference stress lines in the dentine shown in the slices (Extended Data Fig. 6c) at the following day counts: blue, 265; green, 330; cyan, 365; yellow, 420; and red, 455. Sides of teeth indicated by B, buccal; D, distal; L, lingual; M, mesial.

Figure 5. Phylogenetic placement of $N$. alesi. Strict consensus of the ten most parsimonious trees from the unscaled phylogenetic analysis of 265 cranial and postcranial characters (tree length $=1383$; consistency index $=0.289$; homoplasy index $=0.711$; retention index $=0.597)$. N. alesi is placed within the nyanzapithecines, which with the afropithecines 
form the sister group to crown hominoids. See also Extended Data Fig. 8 for bootstrap values and results of scaled analysis.

\section{METHODS}

\section{Locality description and specimen discovery}

Napudet $\left(2^{\circ} 58.103^{\prime} \mathrm{N}, 35^{\circ} 51.969^{\prime} \mathrm{E}\right)$ is located in South Turkana, Turkana Basin, Kenya (see Extended Data Fig. 1g). Sedimentary strata at Napudet were identified as part of the regional mapping of the area by the Kenya Geological Survey ${ }^{36}$. The Koobi Fora Research Project discovered the locality in 1990. I. Nengo relocated the site in 2013, with the help of a team from the Turkana Basin Institute, and directed surveys in 2014 and 2015. KNM-NP 59050 was discovered in 2014 by team member J. Ekusi, and prepared by C. Kiarie at the Turkana Basin Institute.

\section{Stratigraphy and age}

The Napudet Hills are formed by footwall uplift resulting from movement along the Napudet-Loperot Fault, with Miocene and Pliocene strata elevated above the surrounding low relief plains of the South Turkana Desert ${ }^{36,37}$ (Extended Data Fig. 1g). At the northern end of the Napudet Hills, sedimentary strata comprise four sequences, the lowest of which is a volcaniclastic interval informally termed the Emunyan beds here (Extended Data Fig. 2a and Supplementary Table 2), containing abundant fossil wood and scattered but wellpreserved vertebrate fossils. The hominoid fossil KNM-NP 59050 was a surface find at the edge of exposures of the prominent brown bedded tuffs in the lower part of the Emunyan beds. Matrix sediment removed during preparation of the cranium was consistent with derivation from this sedimentary unit.

A basalt flow that underlies the fossiliferous Emunyan sedimentary sequence is dated here by Ar-Ar to $13.31 \pm 0.04$ Myr. Preliminary alternating field demagnetization of an oriented sample of this basalt yielded a normal geomagnetic polarity, suggesting that the basalt formed during either C5AAn (13.03-13.18 Myr) or C5ABn (13.36-13.61 Myr) ${ }^{38}$. Magnetic polarity stratigraphy of the overlying Emunyan beds demonstrated normal polarity for the level of the hominoid fossil, and a normal-to-reversed transition approximately $5 \mathrm{~m}$ above the level of the fossil. Assignment of this transition to the top of Chron C5AAn would suggest an age of slightly older than 13.0 Myr, while correlation to the top of C5ABn would imply a slightly older age of about 13.4 Myr for the hominoid. 
The ${ }^{40} \mathrm{Ar}-{ }^{39} \mathrm{Ar}$ age of sample 15-NPD-03 was determined by high-precision stepheating technique on a MAP-215-50 mass spectrometer in the Noble Gas Laboratory at Rutgers University (Extended Data Fig. 2b and Supplementary Data 3). The sample was petrographically evaluated, crushed, sieved to 300-600 $\mu \mathrm{m}$ size range, washed in distilled water in an ultrasonic bath, and dried in an oven at $\sim 80^{\circ} \mathrm{C}$. The sample was hand-picked and loaded into aluminium irradiation disks along with multiple splits of monitor minerals and wrapped in aluminium foil, and neutron irradiated at $1,000 \mathrm{~kW}$ for $20 \mathrm{~min}$ using cadmiumfoil shielding in the central thimble facility of the US Geological Survey TRIGA reactor in Denver, Colorado. A 40-W $\mathrm{CO}_{2}$ laser with a jogging square laser beam $(6 \mathrm{~mm} \times 6 \mathrm{~mm})$ was used as the thermal source for the incremental-heating experiments. The irradiation parameter $J$ was determined by multiple total-fusion analyses of co-irradiated monitor mineral Fish Canyon Sanidine $(\mathrm{FC}-2=28.201 \pm 0.046 \mathrm{Myr})^{39}$. Age calculations were made using currently accepted decay constants and isotopic abundances ${ }^{40}(1977): \lambda_{\varepsilon}=5.81 \times 10^{-11} \mathrm{yr}^{-1}$, $\lambda_{\beta}=4.962 \times 10^{-10} \mathrm{yr}^{-1},{ }^{40} \mathrm{~K} / \mathrm{K}_{\text {total }}=1.167 \times 10^{-4}$. The following interfering neutron reaction from $\mathrm{Ca}$ and $\mathrm{K}$ values were used ${ }^{39,40}:\left({ }^{36} \mathrm{Ar}-{ }^{37} \mathrm{Ar}\right)_{\mathrm{Ca}}=2.64 \pm 0.02 \times 10^{-4} ;\left({ }^{39} \mathrm{Ar}-\right.$ $\left.{ }^{37} \mathrm{Ar}\right)_{\mathrm{Ca}}=6.73 \pm 0.04 \times 10^{-4} ;\left({ }^{38} \mathrm{Ar}-{ }^{39} \mathrm{Ar}\right)_{\mathrm{K}}=1.34 \pm 0.02 \times 10^{-2}$ from refs 41,42 , and $\left({ }^{40} \mathrm{Ar}-\right.$ $\left.{ }^{39} \mathrm{Ar}\right)_{\mathrm{K}}=2.85 \pm 0.5 \times 10^{-4}$ correction determined from measurements of kalsilite glass. When we plotted the incremental release spectra of the plateau steps identified for sample 15-NPD03 on an isochron plot, it was possible to observe that the ${ }^{40} \mathrm{Ar}-{ }^{36} \mathrm{Ar}$ intercept was not purely atmospheric. Thus, we corrected the data using these trapped ${ }^{40} \mathrm{Ar}-{ }^{36} \mathrm{Ar}$ components. The corrected plateau ${ }^{40} \mathrm{Ar}-{ }^{39} \mathrm{Ar}$ age obtained, $13.31 \pm 0.04 \mathrm{Myr}$, is considered to be the most representative for this sample (Extended Data Fig. 2b).

\section{X-ray microtomography}

KNM-NP 59050 was scanned using propagation phase-contrast X-ray synchrotron microtomography at beamline ID19 of the European Synchrotron Radiation Facility in Grenoble, France. The purpose was to visualize the specimen from a full overview down to virtual histology for the study of dental development. Four configurations were therefore used, providing voxel sizes of $28.06,12.86,3.44$, and $0.74 \mu \mathrm{m}$. All acquisition parameters are summarized in Supplementary Table 3. Extant hominoid crania were scanned for comparative purposes using beamline BM05 of the European Synchrotron Radiation Facility in polychromatic mode (average energy between 100 and $130 \mathrm{keV}$ ), the GE phoenix v|tome|x s240 at the American Museum of Natural History, New York, and the BIR ACTIS 225/300 of the Max Planck Institute for Evolutionary Anthropology, Leipzig. Voxel sizes varied 
between 22.93 and $53.19 \mu \mathrm{m}$ depending on the size of the specimens. VGStudioMax 3.0 (Volume Graphics), Avizo 7.1 (FEI), and Amira 5.6 (FEI) were used for two- and threedimensional visualization, segmentation, reconstruction, and measurements.

\section{Preliminary reconstruction of the cranium}

To make meaningful comparisons possible, a preliminary retrodistortion of KNM-NP 59050 was attempted. This was done first on six orthogonal views using two-dimensional distortion maps to restore symmetry and to compensate for the major fractures (Extended Data Figs 1a$\mathrm{f}$ and $3 \mathrm{a})$. The two-dimensional distortion maps were then applied sequentially in three dimensions to the original image volume of KNM-NP 59050 (Extended Data Fig. 3b). This approach of correcting plastic deformations and fractures should be reasonably reliable for large-scale aspects and to obtain a preliminary estimate of the endocranial volume, but not necessarily with respect to more detailed morphology. A full reconstruction of the cranium will require extensive segmentation of all the bony components affected by cracks and plastic deformation, and subsequent three-dimensional correction of any distortions and misalignments.

\section{Dental development and synchrotron virtual histology}

Dental development in $N$. alesi was investigated quantitatively, using virtual synchrotron palaeohistology ${ }^{17}$ to examine the incremental lines preserved in the enamel and dentine.

Long-period lines and stress patterns were visible in scans with a voxel size of $3.44 \mu \mathrm{m}$ of complete teeth of KNM-NP 59050, and long-period line periodicity could be seen in scans with a voxel size of $0.72 \mu \mathrm{m}$.

Diagenetic factors made it difficult to observe the enamel incremental lines in many of the dental germs. Only the right $\mathrm{I}^{2}$ exhibited a good enough contrast of the microstructures to establish a long-period line periodicity of 5 days (Extended Data Fig. 6d), and this figure was used for the rest of the analysis to calculate time in days.

Although enamel microstructures were not widely visible across the dentition in the $3.44 \mu \mathrm{m}$ scans, dentine showed a very clear incremental pattern at this resolution, with good visibility of Andresen lines (equivalent to Retzius lines in enamel), especially in the right $\mathrm{I}^{2}$ (Extended Data Fig. 6c). Andresen lines were also visible in many other teeth, but not at a clarity that would allow the precise timing of tooth initiation to be documented. Nonetheless, all elements of the dentition exhibit a fairly clear stress pattern with recognizable accentuated lines. By comparing the pattern of the right $\mathrm{I}^{2}$, calibrated against time using the Andresen line 
counts and periodicity, and with identification of the same stress lines in other teeth (Extended Data Fig. 6b, c), it was possible to retrieve the relative dental development sequence for the whole dentition.

For developing tooth germs, the dentine daily secretion rate along the cusp axis (from dentine horn to developing pulp cavity) appears to be relatively constant, as long as the lateral enamel is still extending. We used this property to estimate dental initiation for all the teeth, by measuring the distance along the developmental axis of the cusps, between the dentine horn and the first recognizable reference stress line. Dentine axial daily secretion rates were calibrated for the right $\mathrm{I}^{2}$ and the left $\mathrm{M}^{1}$ and then applied to all the other teeth.

The first visible accentuated line in the $\mathrm{M}^{1} \mathrm{~s}$ was interpreted as the neonatal line, and this line was observable in all cusps except the hypocone. After careful superimposition of the stress pattern across the whole dentition, it was clear that the neonatal line was also visible in the $\mathrm{I}^{1} \mathrm{~S}$ as the uppermost stress line, indicating a prenatal initiation not only of the $\mathrm{M}^{1} \mathrm{~s}$, but also of the $\mathrm{I}^{1} \mathrm{~s}$.

By combining these data, it was possible to quantify the complete dental development (Supplementary Data 4), and to build developmental charts (Fig. 4 and Supplementary Data 4). The age at death was then measured as 485 days after birth with an error margin of 40 days. Crown formation times of the $\mathrm{M}^{1} \mathrm{~s}$ (paracone) and of the $\mathrm{I}^{1} \mathrm{~s}$ are 1.05 and 1.21 years, respectively (average of both sides).

Of special interest is that the $\mathrm{I}^{1} \mathrm{~s}$ in $N$. alesi initiate development very early and complete their growth at the same time as the $\mathrm{M}^{1} \mathrm{~s}$. Considering the rapid extension of the $\mathrm{I}^{1}$ roots, which are longer than those of the $\mathrm{M}^{1} \mathrm{~s}$, the $\mathrm{I}^{1} \mathrm{~s}$ would probably have erupted before, or at the same time as, the $\mathrm{M}^{1} \mathrm{~s}$. This proposition is strengthened by the advanced root resorption of the deciduous $\mathrm{I}^{1} \mathrm{~s}$ and $\mathrm{I}^{2} \mathrm{~s}$, suggesting ongoing eruption of the permanent $\mathrm{I}^{1} \mathrm{~s}$, followed by the $I^{2} s$.

The general dental development pattern of KNM-NP 59050, and the advanced $\mathrm{I}^{1}$ development in particular, were studied in more detail by making comparisons with extant juvenile hominoids and cercopithecoids. These included Pan troglodytes (10), Gorilla gorilla (3), Pongo pygmaeus (4), Homo sapiens (6), Hoolock sp. (4), Hylobates muelleri (1), Nomascus hainanus (1); and the cercopithecoids Papio ursinus (1), Cercopithecus petaurista (1), Macaca sp. (2), and Macaca nigra (1). These specimens are in the collections of the Musée des Confluences de Lyon and were scanned at the European Synchrotron Radiation 
Facility, except for the Hoolock material, which is housed in, and was scanned at, the American Museum of Natural History (New York), as well as Hylobates and Nomascus specimens, which are housed at the Museum für Naturkunde, Berlin, and were scanned at the Max Planck Institute of Evolutionary Anthropology (Leipzig). Results of these comparisons show that the unusual pattern of advanced development of the $\mathrm{I}^{1} \mathrm{~s}$ is found only in Hylobates and Hoolock.

Three dental development characters were coded as part of the character matrix used in the phylogenetic analyses (Supplementary Data 5). These were the relative developmental timing of I1 versus M1, M1 versus M2, and M2 versus P4. These data were taken preferentially from upper teeth when available, but also from lower ones where necessary (assuming a similar developmental pattern in upper and lower dentition). The character states were obtained by direct observations (including online tomography database) and from the literature, on the basis of computed tomography of juveniles, documented eruption patterns, or histological data.

\section{Semicircular canals of the inner ear}

The left bony labyrinth of KNM-NP 59050 is best preserved and analysed here. It was compared quantitatively on the basis of arc shape and size of the semicircular canals, using features known to distinguish hominids, hylobatids, and other catarrhines ${ }^{25,26,43,44}$. Data are provided in Supplementary Table 1. For fossils and the extant hominoids, the arc height and width of each canal ${ }^{25}$ were measured from three-dimensional surface models extracted from microtomographic scans (Extended Data Fig. 7a-1). In the case of extant hominoids, this concerned a model representing the mean shape and size of the sample. Data were also obtained for additional anthropoid species ${ }^{43,44}$, for use in the phylogenetic analyses. The mean radius of curvature of the semicircular canals was scaled against body mass (Extended Data Fig. 7h, ref. 45 and Supplementary Note 1).

\section{Morphological and cladistic analyses}

Specimens examined for the morphological and phylogenetic analyses derived from collections at the American Museum of Natural History, the Harvard Museum of Comparative Zoology, the National Museums of Kenya, Nairobi, and the Center for the Study of Human Origins at New York University. Hominins were not included in the comparative sample, and not considered here when using the terms 'hominoid' and 'hominid'. Extant juvenile specimens were selected to encompass the dental age of KNM-NP 
59050, from erupted deciduous dentition only to full eruption of the $\mathrm{M}^{1}$ and/or $\mathrm{I}^{1}$, some with $\mathbf{M}^{2}$ starting eruption as well (Supplementary Data 2). Adult specimens were defined as those with a completely erupted permanent dentition.

Observations and measurements are based on original specimens, as well as on highquality casts, published photographs, and data provided in the literature. All juvenile data were collected by the authors; adult data were collected by the authors whenever possible, with additional data from ref. 46, PRIMO (access courtesy of E. Delson), and the literature (Supplementary Data 2). Whenever possible, individual specimens were used for statistical comparisons, but in a few cases published species averages were used to include key taxa. Adult features were assessed for KNM-NP 59050 through quantitative and qualitative comparisons with the above-referenced sample of extant juvenile and adult hominoids. Any given morphological feature was deemed to hold constant throughout ontogeny if present in both adult and juvenile extant ape specimens of the taxa examined ${ }^{41}$. These ontogenetically stable features are discussed throughout the main text.

Comparative analyses were based on standard craniometric and dental measurements (Extended Data Table 1 and Supplementary Data 2). Those of KNM-NP 59050 were taken from the original specimen as well as from a high-resolution three-dimensional surface visualization derived from the microtomographic images (Extended Data Figs 1a-f and 3a, b). For comparisons of juvenile crania, the measurements were size-adjusted by dividing each by the geometric mean of 13 cranial measurements (Supplementary Data 2). For comparisons of adult crania, the measurements were size-adjusted on the basis of the square root of $\mathrm{M}^{1}$ area to enable comparisons with key fossil specimens that are invariably too fragmentary to obtain a geometric mean of an adequate set of cranial measurements. The two methods of size adjustment are broadly similar, given that the geometric mean used here and the square root of $\mathrm{M}^{1}$ area are highly correlated $\left(r=0.935 ; r^{2}=0.874 ; P<0.001 ; 61\right.$ adult extant ape specimens). Nevertheless, juvenile and adult specimens were not directly compared, as we only focused on the pattern of morphological differences between taxa. In particular, we examined whether specific patterns were consistently maintained from infants to adults to assess the ontogenetic stability of particular features. For KNM-RU 7290, both the actual $\mathbf{M}^{1}$ area as well as a reduced estimated area were used, aimed at correcting for the megadontia exhibited by E. heseloni ${ }^{47}$ (Supplementary Note 1 ). Statistical analyses were performed in PAST 3.14 (ref. 48) and SPSS version 22.0. 


\section{Phylogenetic analyses}

In addition to general qualitative and quantitative anatomical comparisons, we conducted a parsimony analysis of morphological characters to assess the phylogenetic position and likely evolutionary relationships of $N$. alesi. The morphological character matrix of ref. 8 was supplemented with cranial characters from ref. 29 and several other sources ${ }^{12,49,50}$ (Supplementary Data 5). Twelve new characters were also included, and several character states were modified to accommodate polymorphisms or features found in the broadened taxonomic sample. In some cases, scores differed from the data sets from which they were derived on the basis of our independent qualitative and quantitative assessments of morphology (as indicated in Supplementary Data 5). The taxon sample of ref. 8 was expanded to include additional fossil catarrhines, including Saadanius, Rukwapithecus, Oreopithecus, Afropithecus, Kenyapithecus, Ouranopithecus, Sivapithecus, Lufengpithecus, Hispanopithecus, Pierolapithecus, and the recently described Pliobates ${ }^{12}$. We did not include Mabokopithecus in our analyses because the hypodigm and its relationship to Nyanzapithecus are unresolved and under study ${ }^{51}$. For these additional taxa, scores were based on our own data and observations as well as information provided in the literature; many character codings for Saadanius and Rukwapithecus were taken from ref. 27, while codings for Pierolapithecus, Hispanopithecus, and Pliobates (with modifications) were taken from ref. 12. All characters and character states are provided in Supplementary Data 5 and the matrix is provided as a Nexus file in Supplementary Data 6. In total, 265 characters scored for 47 taxa were included in the analysis, incorporating characters of the skull and postcranial skeleton.

Characters were considered ordered whenever it could be assumed that a population probably passed through an intermediate state to get to an extreme state on either side. In these cases, ordering characters is a much more faithful representation of the evolutionary process (for example, a population does not typically evolve from a small body mass to a large body mass without passing through an intermediate body mass through directional selection $)^{49}$. Polymorphisms were coded as intermediate states between two fixed states whenever possible; simulations suggest that this coding system increases the accuracy of the resulting trees ${ }^{52}$. All other characters were left unordered. Two analyses were performed: one with characters unscaled (that is, all steps given equal weight), and one with multistate, polymorphic characters scaled so that these characters had the same weight as binary and unordered characters (that is, polymorphic steps were downweighted relative to steps between fixed states) (Fig. 5, Extended Data Fig. 8 and Extended Data Table 2). Adult 
character states were estimated for KNM-NP 59050 through quantitative and qualitative morphological comparisons with the above-referenced sample of extant infant and adult hominoids (see, for example, Extended Data Figs 4 and 5). A character state was deemed to hold constant throughout ontogeny if it was present in both adult and infant specimens close to the same dental age as KNM-NP 59050. Wherever it could be safely assumed that a character state held through ontogeny, we scored KNM-NP 59050 accordingly ${ }^{53}$.

The resulting matrix was analysed using a 10,000 replication, random addition sequence heuristic search in PAUP 4.10b. To provide an estimate of clade support, a 1,000replication bootstrap procedure with replacement was performed. A sample of platyrrhines (Aotus (Cebus, Saimiri)) along with the primitive catarrhines Catopithecus and Aegyptopithecus were assigned and constrained as successive outgroups, with the ingroup composed of Saadanius, pliopithecoids, Old World monkeys, dendropithecids, proconsulids, Pliobates, hylobatids, fossil hominids (Sivapithecus, Kenyapithecus, Pierolapithecus, Hispanopithecus, Ouranopithecus, Lufengpithecus, and Oreopithecus), and extant hominids (Pongo, Gorilla, and Pan). Broad-level taxonomy follows ref. 1.

\section{Data availability}

KNM-NP 59050 is available for study at the National Museums of Kenya, and data analysed here are provided in the article and its Supplementary Information files. Image data sets of comparative specimens can be accessed at http://paleo.esrf.eu, http://africanfossils.org, and http://morphosource.org. The species is registered in ZooBank (http://zoobank.org; LSID urn:1sid:zoobank.org:act:BE0A6575-AD3A-4415-A169-6ABC6B8280E2).

36. Dodson, R. G. Geology of the Area South of Lodwar, Degree Sheet 18, N.E. Quarter. Report No. 87 (Geological Survey of Kenya, 1971).

37. Morley, C. K. et al. in Geoscience of Rift Systems - Evolution of East Africa. AAPG Studies in Geology Vol. 44 (ed. Morley, C. K.) 19-54 (American Association of Petroleum Geologists, 1999).

38. Hilgen, F. J., Lourens, L. J. \& Van Dam, J. A. in The Geologic Time Scale (eds Gradstein, F. M., Ogg, J. G., Schmitz, M. D. \& Ogg, G. M.) 923-978 (Elsevier, 2012).

39. Kuiper, K. F. et al. Synchronizing rock clocks of Earth history. Science 320, 500-504 (2008). 
40. Steiger, R. H. \& Jäger, E. Subcommission on geochronology: convention on the use of decay constants in geo- and cosmochronology. Earth Planet. Sci. Lett 36, 359-362 (1977).

41. Dalrymple, G. B., Alexander, E. C. J., Lannphere, M. A. \& Kraker, G. P. Irradiation of Samples for 40Ar/39Ar Dating Using The Geological Survey TRIGA Reactor. US Geological Survey Professional Paper No. 1176 (US Geological Survey, 1981).

42. Dalrymple, G. B. \& Ryder, G. ${ }^{40} \mathrm{Ar} /{ }^{39} \mathrm{Ar}$ age spectra of Apollo 15 impact melt rocks by laser heating and their bearing on the history of lunar basin formation. J. Geophys. Res. 98 (E7), 13085-13095 (1993).

43. Spoor, C. F. The Comparative Morphology And Phylogeny Of The Human Bony Labyrinth. PhD thesis, Utrecht Univ. (1993).

44. Spoor, F. et al. The primate semicircular canal system and locomotion. Proc. Natl Acad. Sci. USA 104, 10808-10812 (2007).

45. Smith, R. J. \& Jungers, W. L. Body mass in comparative primatology. J. Hum. Evol. 32, 523-559 (1997).

46. Chamberlain, A. T. A Taxonomic Review and Phylogenetic Analysis of Homo habilis. Ph.D. thesis, Univ. Liverpool (1987).

47. Rafferty, K. L., Walker, A., Ruff, C. B., Rose, M. D. \& Andrews, P. J. Postcranial estimates of body weight in Proconsul, with a note on a distal tibia of P. major from Napak, Uganda. Am. J. Phys. Anthropol. 97, 391-402 (1995).

48. Hammer, Ø., Harper, D.A.T., Ryan, P.D. PAST: paleontological statistics software package for education and data analysis. Palaeontol. Electronica 4, 4 (2001).

49. Moyà-Solà, S. \& Kohler, M. New partial cranium of Dryopithecus Lartet, 1863 (Hominoidea, Primates) from the Upper Miocene of Can-Llobateres, Barcelona, Spain. J. Hum. Evol. 29, 101-139 (1995).

50. Cameron, D. W. A revised systematic scheme for the Eurasian Miocene fossil Hominidae. J. Hum. Evol. 33, 449-477 (1997).

51. Benefit, B. R., Gitau, S. N., McCrossin, M. L. \& Palmer, A. K. A mandible of Mabokopithecus clarki sheds new light on oreopithecid evolution. Am. J. Phys. Anthropol. 105 (Suppl. 26), 109 (1998). 
52. Wiens, J. J. in Phylogenetic Analysis of Morphological Data. Comparative Evolutionary Series (ed. Wiens, J. J.) 115-145 (Smithsonian Institution Press, 2000).

53. Gilbert, C. C., Stanley, W. T., Olson, L. E., Davenport, T. R. B. \& Sargis, E. J. Morphological systematics of the kipunji (Rungwecebus kipunji) and the ontogenetic development of phylogenetically informative characters in the Papionini. J. Hum. Evol. 60, 731-745 (2011).

54. Isler, K. et al. Endocranial volumes of primate species: scaling analyses using a comprehensive and reliable data set. J. Hum. Evol. 55, 967-978 (2008).

Extended Data Figure 1. KNM-NP 50950 and Napudet. a-f, Specimen as preserved in left lateral view (a), anterior view (b), right lateral view (c), superior view (d), posterior view (e), and inferior view (f), visualized using three-dimensional X-ray microtomography. g, The Napudet locality on the western side of Lake Turkana, Kenya.

Extended Data Figure 2. Stratigraphy and dating. a, Stratigraphic sections at localities CSF 2015-1, -2 and -3, and placement of KNM-NP 59050 (orange star). See Supplementary Table 2 for associated GPS coordinates. b, Incremental release spectra for sample 15-NPD03 , corrected for the trapped ${ }^{40} \mathrm{Ar}-{ }^{36} \mathrm{Ar}$ component. The plateau obtained provided the most representative age for this sample (see Methods for details).

\section{Extended Data Figure 3. Cranial comparison of KNM-NP 59050 with juvenile} catarrhines. a, KNM-NP 59050 as preserved. b, KNM-NP 59050 as retrodistorted, c, Hoolock sp. d, G. gorilla. e, P. troglodytes. f, P. pygmaeus. g, P. ursinus. Each specimen is shown, from left to right, in posterior, left lateral, anterior, superior, and inferior views. Rendering size is standardized on the basis of overall cranial size. Scale bars, $2 \mathrm{~cm}$.

Extended Data Figure 4. Juvenile and adult facial size. a-d, Boxplots of relative snout size expressed by orbitale inferior to prosthion $(\mathbf{a}, \mathbf{b})$ and maxillary height from orbitale inferior to the alveolar margin $(\mathbf{c}, \mathbf{d})$. Values are size-adjusted on the basis of a geometric mean of cranial measurements for juveniles (a, c) and the square root of $\mathrm{M}^{1}$ area for adults (b, d). Hylobatids have significantly smaller snouts than extant great apes (analysis of variance (ANOVA) with Bonferroni correction, $P<0.01$ ), both in juveniles and in adults. KNM-NP 59050 falls in the range of extant hylobatids. e, Orbit size (square root of maximum height $\times$ breadth in millimetres) compared to cranial size (geometric mean in millimetres) for KNM-NP 59050 (star), as well as for juvenile hylobatids (circles), Pongo 
(triangles), and African great apes (squares). Box and whiskers as in Fig. 3, and samples are given in Supplementary Data 2.

Extended Data Figure 5. Juvenile and adult cranial features. a, b, Boxplots of interorbital breadth in juveniles (a) and adults (b), size-adjusted as in Extended Data Fig. 4a-d. Hylobatids and African great apes have significantly greater interorbital breadth than Pongo (ANOVA with Bonferroni correction, $P<0.01$ ), both in juveniles and in adults. KNM-NP 59050 falls exclusively in the range of extant hylobatid juveniles. c, d, Boxplots of the nasal aperture width in juveniles (c) and adults (d), size-adjusted as in Extended Data Fig. 4a-d. Pongo has a significantly narrower nasal aperture than African great apes both in juveniles and in adults (ANOVA with Bonferroni correction, $P<0.01$ ). KNM-NP 59050 falls closest to the median of extant Pongo juveniles. e, f, Ratio of nasion-bregma/bregma-lambda in juveniles (e) and adults (f). Hylobatids have a significantly greater ratio compared with the great apes (ANOVA with Bonferroni correction, $P<0.01$ ) both in juveniles and in adults. KNM-NP 59050 falls exclusively in the range of extant great ape juveniles, a ratio probably maintained into adulthood. Box and whiskers as in Fig. 3, and samples are given in Supplementary Data 2.

Extended Data Figure 6. Virtual histological slices of KNM-NP 59050. a, Threedimensional rendering of the right unerupted permanent teeth germs. b, Virtual histological slices of these teeth with coloured arrows showing the stress lines in dentine used for developmental cross-correlations of all the teeth and cusps. Scale bar, $5 \mathrm{~mm}$. c, Detail of the Andresen lines in the dentine, and reference stress lines in the right $\mathrm{I}^{2}$ germ. Colours correspond to the lines represented in Fig. 4. Scale bar, $1 \mathrm{~mm}$. d, Details of the enamel microstructure of this tooth, showing four daily lines (dark orange arrows) between consecutives Retzius lines (light orange arrows), indicating a long-period line periodicity of 5 days. Scale bar, $100 \mu \mathrm{m}$.

Extended Data Figure 7. Endocranial volume and the bony labyrinth. a, b, Bivariate double logarithmic plots of the endocranial volume (a, ECV, in millilitres) and the mean radius of curvature of the three semicircular canals (b, SC-R, in millimetres) against body mass (BM, in grams) for extant hominids (blue dots), hylobatids (cyan dots), cercopithecids (small open triangles), and strepsirrhines (small black diamonds, a only), Aegyptopithecus (black square), Pliobates (purple dot, a), Saadinius (purple dot, b), Victoriapithecus (grey triangle), Ekembo (magenta dot), Oreopithecus (orange dot), Hispanopithecus (green dot), Rudapithecus (teal dot), and KNM-NP 59050 (red dot). For KNM-NP 59050 and 
Oreopithecus (b only), the line represents a range of body mass values (Supplementary Note 1). Reduced major axis regression lines are given for the extant hominids, hylobatids (a only), cercopithecids, and strepsirrhines (a only). Data from refs 43-45, 54 and Supplementary Note 1 and Supplementary Table 1. c-n, Lateral (c-h) and superior (i-n) views of the left bony labyrinth of $P$. troglodytes $(\mathbf{c}, \mathbf{h}), G$. gorilla $(\mathbf{d}, \mathbf{j})$, Pongo abelli $(\mathbf{e}, \mathbf{k})$, KNM-NP 59050 (f, l), Symphalangus syndactylus (g, m), and H. muelleri $(\mathbf{h}, \mathbf{n})$. Scale bar, $5 \mathrm{~mm}$. The extant species are represented by mean shapes of between 6 and 39 specimens per species (Supplementary Table 1).

Extended Data Figure 8. Phylogenetic analyses of $N$. alesi. Strict consensus trees of the unscaled (a) and scaled (b) analyses showing the placement of KNM-NP 59050 as part of the Nyanzapithecus clade. Trees show the summary of ten most parsimonious trees (unscaled: 1382; consistency index $=0.289$; homoplasy index $=0.711$; retention index $=0.597$ ) and three most parsimonious trees (scaled: $\mathrm{TL}=1274.25$; consistency index $=0.288$; homoplasy index $=0.712$; retention index $=0.599$ ). Numbered nodes correspond with clades listed in Extended Data Table 2. Bootstrap support values $>50 \%$ (1,000 replicates) are shown below nodes. Note that in the unscaled analysis, a Sivapithecus + Pongo clade is supported in $72 \%$ of bootstrap replicates, but not found in the strict consensus tree.

\section{Extended Data Table 1 Dental and cranial dimensions compared}

a, Mesiodistal (MD) and buccolingual (BL) or labiolingual (LL) dimensions of the $\mathrm{I}^{1}, \mathrm{M}^{1}$, and $\mathrm{M}^{2}$ crowns as well as the $\mathrm{I}^{1}$ labial crown height $(\mathrm{CH})$ of KNM-NP 59050 and other nyanzapithecine specimens. b, Cranial dimensions of KNM-NP 59050 and extant hylobatid specimens of the same infant dental age. Measurements marked by ' $r$ ' were taken from a retrodistorted model of KNM-NP 59050. Linear measurements given in millimetres, and those in parentheses are estimates. Endocranial volumes given in millilitres. Means and ranges of adult endocranial volumes after ref. 54. For further details see Supplementary Data 2 .

\section{Extended Data Table 2 Selected synapomophies suggested by character transformational analysis}

Listed characters represent those suggesting a character-state transition at the corresponding node. Character states in bold are recognized as notable synapomorphies appearing only in the clade listed. 
*Those character states reconstructed as synapomorphies for a given clade, but also appearing elsewhere on the tree or incurring reversals within the clade.

$\dagger$ Reconstructed synapomorphy uncertain owing to absence of preservation in most fossil taxa. Character numbers as listed in Supplementary Data 5 and 6. See Extended Data Fig. 8 for trees with corresponding clades; synapomorphies reconstructed from the most parsimonious trees in the unscaled analysis. 